\title{
Ground Control to Architect Tom...
}

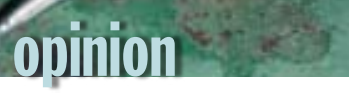

Alex Bell, The Boeing Company
$\mathbf{P}$ roject managers love him, recent software engineering graduates bow to him, and he inspires code warriors deep in the development trenches to wonder if a technology time warp may have passed them by. How can it be that no one else has ever proposed software development with the simplicity, innovation, and automation being trumpeted by Architect Tom? His ideas sound so space-age, so futuristic, but why should that be so surprising? After all, Tom is an architecture astronaut! ${ }^{1}$

Architecture astronauts such as Tom naturally think at such high levels of innovation because they spend much of their time in high orbit where low oxygen levels counterbalance the technological shackles imposed by reality.

Little did I know it at the time, but my daughter stumbled upon several foundational tenets of architecture astronautics years ago while watching a cartoon on TV called Princess Gwenevere and the Jewel Riders. One Saturday morning, while Princess Gwenevere was relentlessly fighting the forces of evil in the fairy tale land of Avalon mounted atop her beloved unicorn Sunstar, my daughter asked, "Daddy, are unicorns real?" I quickly debated the tactics I should take in my answer and decided that honesty and reality would be my guiding beacons. The ensuing discussion was short: unicorns were real because my daughter wanted them to be, and just as importantly, because I could offer no proof to suggest otherwise.

This seemingly innocuous exchange, historically known as the "Sunstar Impasse of 1996," raised my awareness of a tactic that is most certainly described on page 1 of the official Architecture Astronaut Handbook. Specifically, "An architecture astronaut in good standing shall exploit the difficulties of proving nonexistence." For example, let's say that Architect Tom draws a time machine with an impressive array of dials and switches, describes its behavior with some complex yoo-mel diagrams, and then declares that the device's remaining production effort is merely an annoying detail. How does someone prove that this time machine cannot be built when Architect Tom says that it can? Nonexistence arguments such as this one are further complicated when they involve people who are desperately reliant on the premise of some item's existence to fulfill their own commitments

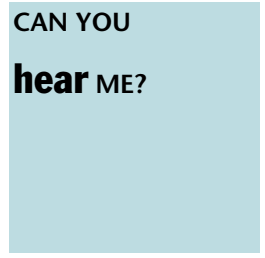

and responsibilities.

Another foundational tenet most certainly included in the Architecture Astronaut Handbook can be best exemplified by returning to the context of Avalon where Princess Gwenevere's fellow Jewel Riders, Tamara and Fallon, enter the picture with their unicorns and magical enchanted jewels. On the occasions when my daughter invited friends to come over and watch the Jewel Riders with her, it was not unusual to overhear debate among them as to which of the Jewel Riders was the prettiest, which had the nicest unicorn, or which enchanted stone was the most desirable. Architecture astronauts similarly debate such fictional truths among themselves without the slightest concern that the bases of their debates have no correlation with reality.

An example of an inane debate possibly occurring between members of the Fraternal Brotherhood of Astronauts might involve one astronaut asking another, "Is it preferable to ride a unicorn or a magic carpet to work?" The ensuing discussion would most certainly involve trading off the high costs of unicorn food versus the comfort of 200-knot-per-square-inch magic carpets. Speaking of inane debate, I wonder which one of the Jewel Riders would be the most attracted to me if I were to travel to Avalon. My wife would undoubtedly suggest it to be the one holding a white cane atop a seeing-eye unicorn.

Architecture astronauts do not like to use "old" software technologies or design tactics because today's offerings are much more powerful than those used in the development of existing systems. Astronauts prefer new things, such as the innovation of distributed computing enabled by Web services and the novelty of self-describing data that is only now possible with the availability of XML. It is entertaining to ponder what an architecture astronaut might do if assigned the task of inventing a modern version of the wheel. Because today's astronauts are so much better educated and technologically equipped than the caveperson who invented the first wheel millions of years ago, they would probably assume that the idea of a round wheel is somehow wrong, opt for a square 
one, and judge society to be ignorant for not having created a need for square wheels. Of course, the wheel has been greatly improved since the days of being chiseled from stone, but the value of some ideas is timeless.

Architecture astronauts are easy to recognize because they exhibit a number of signature qualities. One of the most prominent of those qualities is an uncanny ability to speak confidently on topics that momentarily humble even the experts. A few probing questions are usually sufficient to expose even the most seasoned of astronauts, but there are not always sufficiently knowledgeable people present to short-circuit oxygen-deficient discussions or the damage-control activities that may be required as a result. Architect Tom and his co-orbiters further demonstrate their astronautic allegiance by habitually speaking at extremely high levels of abstraction. ${ }^{2}$ This is a very important tactic because it helps astronauts avoid engaging in tangible discussions that might lead to disclosure that they really have no idea what they are talking about.

At some point in the journey of a project being led by architecture astronauts, the wheels on the spaceship begin to wobble and spacesuits show the first signs of transparency. It is usually a lack of tangible progress demonstrating the legitimacy of the astronautic vision that triggers concern. Beyond the traditional diversionary tactic of declaring the design and development staff too incompetent to realize the vision, the astronauts use a shell game to add extra ticks to the reality acceptance countdown. In the astronaut shell game, Architect Tom creates new acronyms or concepts, representing metaphorical shells, to counter any concerns. In response to the creation of these metaphorical shells, the reality-reverent must assume still further burden by proving that the new shells have no technological peas under them.

Architect Tom's winning strategy is to create new shells at a faster rate than the void of peas under them can be demonstrated. The clever astronaut carefully manages his shells so that a project is cancelled before anyone realizes that he never had any peas in the first place. This cancellation scenario, however, is keeping the reality-reverent awake at night, mortified that the architecture astronauts may not see their well-deserved day of reckoning.

Even after an astronaut has been exposed as such and escorted out the door, a phenomenon known as "astronautic hysteresis" has the undesired effect of prolonging the effects of an oxygen-deficient vision upon a project. The damping coefficient associated with this hysteresis is directly related to the number of junior astronauts left behind with an implicit duty faithfully and blindly to promote the decaying vision. The damping coefficient of astronautic hysteresis, however, can be significantly increased by restricting spoken and written usage of reality-deficient terminology.

How can architecture astronauts be placed in positions of significant influence on the technical trajectory of a project? What qualifications entitle them to have the title "architect" printed on their business cards or appended to their e-mail signatures? I suspect that the credential my wife earned in a food-handling course entitling her to sell hot dogs at our son's track meets represents more qualification for doing her job than many architecture astronauts could produce for doing theirs. My wife, however, does not misrepresent herself as a nacho architect.

There is no evidence to suggest that the architecture astronaut continuum will cease to exist any time soon; astronauts will continue to be hired, exposed, and fired. As a result, software projects will continue to be susceptible to the continuum's accompanying carnage unless companies adopt tactics to defend against it. For example, the time has long passed for many software organizations to protect themselves from the damaging effects of architecture astronautics by requiring some form of credential or training before allowing their employees to call themselves architects or assume the responsibilities of one.

Are you diverting the technical efforts of your program from following a realistic and value-added trajectory? If so, fear not, there is hope. A flourishing segment of the global marketplace is being fueled by astronauts who have recognized a need to get out of high orbit and restore the constraints of reality to their thinking. Flavors such as peppermint, bayberry, and cranberry are just a few of many promising to revitalize your deprived brain from the consequences of being in high orbit. Plan to take some flavorful breaths soon at an oxygen bar near you!

Can you hear me Architect Tom?

Can you hear me Architect Tom? Q

\section{REFERENCES}

1. Spolsky, J. 2001. Don't let architecture astronauts scare you. Joel on Software, April 21. http://www.joelonsoftware.com/articles/fog0000000018.html.

2. Also noted by Joel Spolsky in reference 1 .

\section{LOVE IT, HATE IT? LET US KNOW}

feedback@acmqueue.com or www.acmqueue.com/forums

ALEX BELL is a software architect with The Boeing Company. He has written several pieces for ACM Queue including "Death by UML Fever" (March 2004).

○) 2007 ACM 1542-7730/07/0900 $\$ 5.00$ 